\title{
Smart City as a Service System: A Framework to Improve Smart Service Management
}

\author{
Francesco Polese, Antonio Botti, Antonella Monda*, Mara Grimaldi \\ Department of Business Science-Management \& Innovation Systems, University of Salerno, Fisciano, Italy \\ Email: fpolese@unisa.it, abotti@unisa.it, ‘anmonda@unisa.it, margrimaldi@unisa.it
}

How to cite this paper: Polese, F., Botti, A., Monda, A. and Grimaldi, M. (2019) Smart City as a Service System: A Framework to Improve Smart Service Management. Journal of Service Science and Management, 12, 1-16.

https://doi.org/10.4236/jssm.2019.121001

Received: September 29, 2018

Accepted: December 25, 2018

Published: December 28, 2018

Copyright $\odot 2019$ by authors and Scientific Research Publishing Inc. This work is licensed under the Creative Commons Attribution International License (CC BY 4.0).

http://creativecommons.org/licenses/by/4.0/

\begin{abstract}
The paper proposes the re-conceptualization of the smart city as a service system, in line with the recent service theories, such as Service-Dominant logic and Service Science, Management, Engineering, and Design. Starting from a short literature review about service system and smart city, a model characterized by a reticular configuration is proposed. The framework identifies the most adequate organizational layout to foster resources exchange, value co-creation and enhance co-learning among multiple actors. The goal is to highlight that the development of collaborative logics, resulting in continuous processes of cooperation between public and private decision-makers and citizens, allows multiplying moments of value creation as a result of synergistic interactions. This collaborative logic involves citizens, who are seen as a system of customers with whom objectives and knowledge are shared and with which the engagement must be sought, as they represent fundamental partners in achieving the specific objective of value co-creation. The proposed framework highlights the systemic nature of both the smart city and the service system and proposes practical and theoretical implications for public and private services management.
\end{abstract}

\section{Keywords}

Smart City, Service System, Service Management, ICT, Citizen Engagement

\section{Introduction}

In recent years, we have assisted to the increase in urban population. In 1950, cities hosted $30 \%$ of the world's population, today it is $50 \%$, in 2040 it will be $75 \%$. Urbanization led to negative externalities from different points of views: environmental, economic, social. For this reason, the increase in urban population in the world required for constructive response to problems of different order and 
the generation of numerous cities able to manage private and public services effectively and smarter, answering to the needs of citizens and territory with sustainable and innovative solutions. Such cities, that have been able to adapt wisely to the required change, were so called smart cities. At nowadays the term smart city represents a complex concept that is used to describe the cities that, through innovative governance, improved the standard of living of the inhabitants and the economic and environmental development. Caragliu et al. [1] defined a city as "smart" when "investments in human and social capital and traditional (transport) and modern (ICT) communication infrastructure fuel sustainable economic development and a high quality of life, with a wise management of natural resources, through participatory action and engagement".

Smart city, therefore, can be seen as system [2], which is based on a participatory government, in which different actors face negative externalities thanks to technological innovation, the production of renewable energy, the need for a sustainable use of resources and above all thanks to the Information Communication Technologies (ICTs). These are considered a necessary condition for the totalizing growth of the city itself, as their use makes the infrastructural components and services more intelligent, more interconnected and efficient [3] thus fostering social learning and citizen engagement.

From this point of view, the concept of smart city can be seen in line with some recent service theories, such as Service-Dominant logic (S-D logic) [4] [5] [6] and Service Science, Management, Engineering, and Design (SSMED or Service Science) [7] [8], which adopt a holistic vision to the service management. Such theories are based on a service-based logic according to which, in an economic exchange, the collaboration between two or more actors becomes central, as it fosters the exchange of knowledge and skills, generating value and improving the well-being of all participants to the exchange [4]. Specifically, the Service Science, argues that this exchange of resources is facilitated by the predominant role of ICT, that speed social learning and helps engagement among actors [7].

Although many studies tried to offer innovative insights for public and private services management in order to meet the needs of the community and more in general towards achieving efficiency, the transformation of a city into a smart city is a complex process that requires a profound innovation of infrastructure and an important change in the way people live and think.

A possible solution could be to approach the smart city through the lens of the recent service theories, which adopt a holistic vision to the service management and identify the "service system" as the most appropriate organizational model to support the emergence of value also in public service.

Since few studies approach the smart city through the lens of the recent service theories [9], the present study proposes to fill this gap, re-conceptualizing the smart city as a service system, comparing the two entities using the service system model to re-read the smart city. Specifically, the research questions posed are as follows:

RQ1: Is it possible to find the elements of the service system in the smart city? 
RQ2: How these elements relate to each other?

The rereading of the smart city as a service system allows us to create a theoretical framework matching the fundamental key points of the first with the drivers of the second. The proposed model is characterized by a reticular configuration, within which the adequate variety of cognitive knowledge guarantees the harmonization with the other network resources. The development of collaborative logics, resulting of continuous processes of cooperation between public decision-makers and citizens, allows to multiply moments of value creation as a result of synergistic interactions, that are facilitated by the constant search for user engagement, which represents fundamental partners in achieving the value co-creation; contributing to the production of the service by becoming in fact co-responsible for the supply [10].

The originality of the work lies in the application of a new holistic perspective to smart city conceptualization, which takes into account the influence of ICTs on user's knowledge and on service innovation. Moreover, the application of the Service Science, as a lens to re-conceptualize the smart city, allows the implementation of a systemic framework that highlights the systemic nature of both the smart city and the service system.

\section{Service Theories: From a Good-Dominant Logic to a Service-Dominant Logic}

The recent development of marketing led to the progressive reformulation of some of the classical concepts and the birth of new research currents and theories. These theories, such as Service-Dominant logic [4] [5] [6] and Service Science [7] [8], mark the transition from a manufacturing logic, based on the predominance of tangible goods, to a new service-based conceptualization of the value creation process and aim to better manage relations between companies and customers, qualifying the service as a way of exchange to himself. The service-based logic provides the centrality of the collaborative aspects in economic transactions that make the consumer as an integral and decisive part of the process. The firm is a producer of resources used by the customer, considered as the value creator [11]. All the economic actors involved in the exchange are therefore "resource integrators" in an A2A reticular approach ("actors to actors") [12], in which actions are taken to achieve mutual benefits for each.

In this new logic also the object of the exchange changes, it is no longer tangible but composed of knowledge and immaterial capacity, whose value is co-produced with the consumer and determined by himself. Therefore, consumer becomes a main actor which, exchanging resources with the company, generates a process of integration of resources consisting of the set of "procedures, tasks, mechanisms, activities and interactions which support the co-creation of value" [13], carried out by both the consumer and the provider with a view to joint interaction. The ultimate result desirable from this joint interaction is the generation of new intangible resources that lead to a co-creation of value and, therefore, to the well-being of all the participants in the exchange. 


\subsection{The Theory of the Service Science}

While the S-D logic constitutes a solid theoretical basis for the analysis of services, providing "right perspective, vocabulary, and assumptions on which to build a theory of service systems" [8] (p. 19), the Service science represents a practical application of the theory developed by Vargo and Lusch [4], which identifies the practical implications deriving from the concrete implementation of these concepts and deals with studying the implications that the adoption of new management approaches to services involves. The idea of building a service science stems from an initiative of IBM, developed following the transition of the company towards a service centered perspective and undertaken with the aim of creating a platform for systematic service innovation

The theory of Service Science is a multidisciplinary discipline that studies the implications emerging from adopting new management approaches to services. Born due to company's shift from a good-logic to a service centred perspective, the theory aims to combine and to apply computer science, operational research, industrial engineering, management and social sciences to find the most appropriate organizational model to support the emergence of value [7].

According to Maglio and Spohrer [14], the Service Science aims at the pursuit of effectiveness, efficiency and sustainability of services. This service theory consists of four parts (giving the name to the strand):

1) Science, that is the application of scientific principles to the study of services and their evolution;

2) Management, services management to make their design and delivery systems more efficient and achieve a sustainable competitive advantage through lasting systemic relationships;

3) Engineering, services engineering with the aim of developing the methods capable of creating new technologies to improve both the provision and the detection, measurement and dissemination of information;

4) Design, the design of the service systems, which consists in identifying the most suitable configuration techniques for an optimal structuring of the systems themselves.

Service science focuses on the research of methods of scientific analysis to maximize productivity and solve the apparent limitations related to the nature of the services (heterogeneity, intangibility, inseparability, perishability), aiming to realize the engineering, as well as the standardization of the processes underlying "provision of services-in accordance with the changing needs dictated by globalization-with particular attention to the role of knowledge, then the strategic management of human resources, and the provision of technological tools to systematically promote innovation.

\subsection{The Service System: An Organizational Model}

The founders of SSMED consider the service as a system of interacting and interdependent parts that includes people, technologies and organizations; these 
components are used to generate the distinctive characteristics of a company, to achieve and maintain a sustainable competitive advantage [7] [8]. In agreement with the S-D logic, the service is seen as a combination of different dimensions, managerial, technological and cultural, three profiles to be constantly considered in order to gain a lasting competitive advantage [15]. For this reason, the most appropriate organizational model to the emergence of value is represented by a model that takes into account these three profiles, that is the service system.

It represent a theoretical construct aiming to share perspective and vocabulary among different disciplines [8]. Service systemultimate aim is the interconnection of the organization, human understanding and technological understanding to value co-creation. Specifically, its main elements are [7] [16]: people, organization, technology, shared information. Figure 1 is provided the proposal of a graphic representation of the service system.

In a service system, the dimension of "people" is intended as all the actors involved in the service supply process, therefore both providers, consumers, and any other stakeholders. The "organization" is an entity that establishes relationships with its stakeholders in order to create value with them. About the "share information", according to Service theories, people and organization exchange information to enhance the coordination mechanisms of the service system. Vargo and Lusch [5] argue that the object of this exchange can be tangible (operand resources, such as monetary capital, raw material, etc.) or immaterial (operant resources, such as skills, knowledge, experience, know-how culture, habits, etc.). These latter resources play a predominant role in value co-creation, as resource sharing represents the conceptual resource to which all stakeholders can access in a service system to create value [5].

In every service system, immaterial resources are exchanged among the actors of the service.

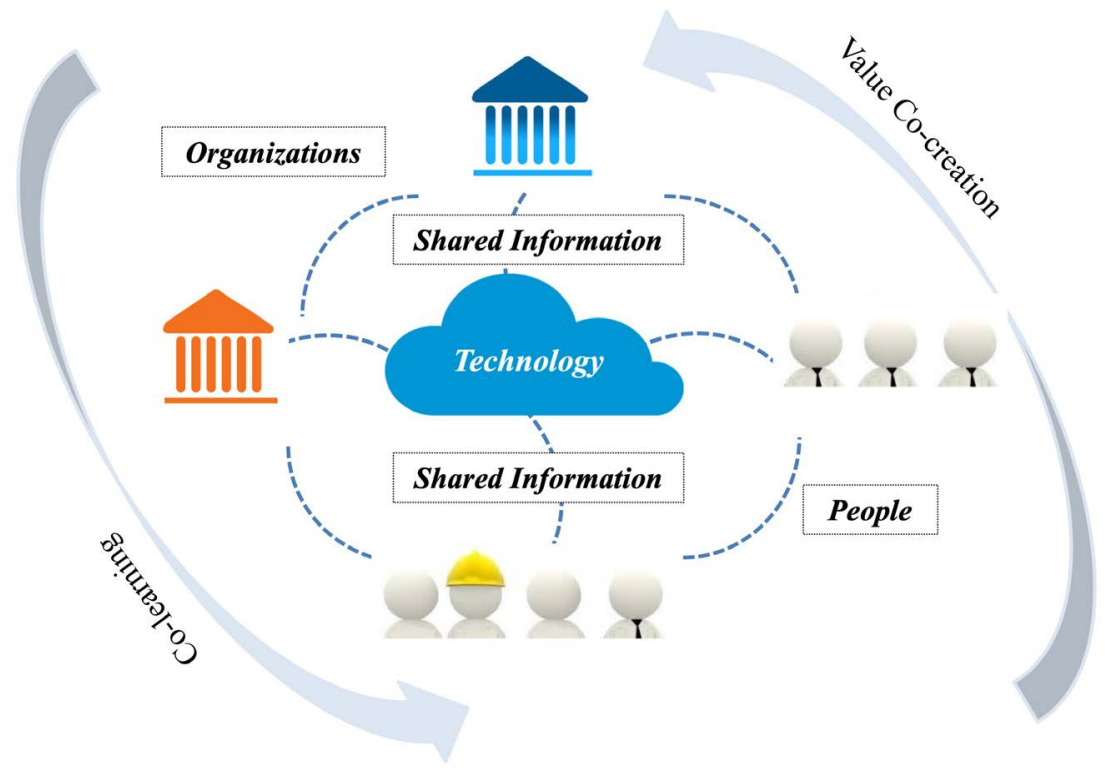

Figure 1. Graphical representation of the service system. 
Lastly, technology and ICTs make services more effective and efficient fostering the exchange of resources between people and organization and speeding social learning, fostering co-learning. Promoting the sharing resource process, the technology and, specifically, ICTs also are seen as facilitator of actors engagement [7].

\section{Smart City}

The concept of Smart City was born and developed over time, using different names that tried to identify similar concepts. However, the definitions made do not always indicate the same idea of a city. The term "smart" refers to many adjectives that qualify a city, such as Intelligent City, Knowledge City, Digital City and much more; this ambiguity in the meaning of the term "smart" could depend on the fact that it represents a very vague concept in today's culture, often used to identify objects that improve people's lives.

Specifically, from an ICT-based point of view, the adjective "smart" indicates an efficient, modern, sustainable city. In this context, Smart City arises from the need to set forward-looking policies for the sustainable development of the city, reinforcing some very important themes for the contemporary city: technological innovation, renewable energy production, the need for sustainable use resources and Information Communication Technologies (ICT). These last are considered a necessary condition for the totalizing growth of the city itself, in fact, the use of ICT makes infrastructures and services more intelligent, more interconnected and efficient [17].

From a knowledge-based point of view, instead, the smartness is linked to the humanistic aspect, related to the importance of social leaning, education, social capital and social sustainability for developing the smart city (Holland, 2008). This perspective considers the smart cities as "territories with a high capacity for learning and innovation, which are built-in the creativity of their population, their institutions of knowledge creation, and their digital infrastructure for communication and knowledge management" [18] (p. 1).

A more generic and comprehensive view of the "smart" concept includes different aspects, from the most technological to those related to social capital and humanistic aspects. Consequently, also a smart city includes different aspects, focusing simultaneously on the role of ICT infrastructure, on the role of human, social and relational capital and on environmental issues [1].

\subsection{Smart People and the Smartness}

The complexity of the smart city makes it necessary to entrust decision-making to different actors, who are distinguished by degrees and levels of interdependence and thanks to their contribution it is possible to develop and implement innovations in cities, at multiple levels. It follows that the mechanisms underlying the creation of a smart city are "multi-level dynamic interaction of factors and stakeholders that contribute to processes that influence economic performance, 
social processes, environmental dynamics and quality of governance at local, national, regional level" [19].

In a smart city based essentially on efficiency the convergence between technological elements and humanistic aspects, translates into integration of ICT and active participation of citizens, this implies the need for a new type of governance characterized by the authentic involvement of citizens in public policy [20]. In fact, technological innovation allows citizens to play a predominant role in the management of the urban context. Through the sharing of information, they are increasingly closer to the city as they are increasingly involved in public decisions.

In answer to the multilevel nature of the smart city, the Centre of Regional Science di Vienna develop a research in which are identified six parameters or dimensions on the basis of which an intelligent city can be identified on an operational level; the dimension are Smart Economy, Smart Mobility, Smart Environment, Smart People, Smart Living, Smart Governance. These are strategies related to the use of ICT technologies that a city should be able to put in place to improve the quality of economy, mobility, the environment, people, living, governance. Among these, the Smart People concept plays a key role in the promotion of human and social capital, stimulating participation in public life, the level of qualification of citizens, the coexistence of different stakeholders and the community, interaction and continuous dialogue to detect concrete needs and make the response efficient and effective. This parameter focuses on the importance of people within the city, they are seen as an indispensable element to be taken into consideration and as an engine of smartness. Depending on the presence or absence of these six parameters, Cohen [21] analyzed European cities and drawn up the ranking of the ten "smart cities" that would be composed, in order, from: Copenhagen, Amsterdam, Vienna, Barcelona, Paris, Stockholm, London, Hamburg, Berlin and Helsinki

\subsection{The Drivers of the Smart City}

In agreement to the idea of a smart city based on aspects related to efficiency, technological and human capital, Naphade et al. [2] identify 4 drivers of the smart city: urbanization, economic growth, technological progress, environmental sustainability.

Urbanization stimulates the creation of smart cities as poses some challenges to social and economic progress [22], linked to the infrastructure and institutional settings [23] such as the public safety, sustainability, technological innovation, the management of traffic congestion and energy consumption.

About the economic growth, the combined contribution of a group of people give birth to a community that stimulates creativity and entrepreneurship, which, in turn, foster the economic activity of smart cities [2]. For this reason, in the nineties, we have witnessed the emergence of smart communities, that is a wide virtual community that goes from a small neighbourhood to a community at a national level, whose members, organizations and administrative institutions 
work in partnership and in the name of a shared goal using information technologies [24]. The integration of actors and resources contributes to the increase in world economic and world wealth [25].

The technology is a possible instrument on which to invest in order to develop distinctive skills of the territory to compete in the global arena. Through ICTs it is possible to obtain and analyze a large amount of data (big data) which can lead to the development of new ideas to improve different services in the city [26] [27]. The integration of data from heterogeneous sources must be managed through cloud platforms, useful for collaboration between multiple organizations or between organizations and citizens, thus encouraging the engagement of citizens. An all-pervasive computational infrastructure is an essential technological component for the construction of a real digital city, since it allows to create real-time connections between the actors and foster engagement.

Finally, the sustainability is the last driver of smart city. The growing demand for a more sustainability can be intended both the development of sustainable urban infrastructures for environment protection and reduction of $\mathrm{CO} 2 \mathrm{emission}$ and social sustainability [28] [29]. In terms of environmental sustainability, the challenges required of the smart city concern the correct use of energy and water resources, adequate waste disposal and the reduction of greenhouse gas emissions [2]. In terms of social sustainability, a smart city is pushed to work on the livability in terms of human rights, social justice, corruption, social and health equity, cultural competence, social responsibility, stakeholder participation [30] [31].

\section{Research Methodology}

Starting from a literature review about the smart city and the service system, the aim of the paper is to provide a re-conceptualization of smart city as a service system.

First, it collected information about the service based theories ontology, and specifically about the theory of the service science. Afterward, it analyzed the smart city ontology and its practical elements. Lastly, it identified the similarities between the service system and the smart city and matched through a holistic approach. This allowed to re-configure the smart city as a service system, following the framework of Spohrer et al. [32]. Finally, a new framework is provided to better manage the dynamics underlying service management. The framework could provide insights to help the management of the smart city, according to the service system model.

This paper is based on a qualitative approach, since it is a theoretical paper, that could represent the basis of discussing future relevant empirical investigations.

\section{The Application of Service System to the Smart City}

The will to apply the model of the service system to the smart city, led the au- 
thors to trace every single element of the service system in the smart city. More specifically, the types of people, organizations, technologies and shared information are identified within the smart city.

"People" in Smart city_If "people" in service system are intended as all the actors involved in the service supply process [7], then in a smart city people are all the actors of a city, both service providers, citizen, and any other stakeholders. The literature shows that the human component, and in particular the consumer/citizen, is a key factor for the progress of the community and for the creation of value and innovation, both in the service system and in the smart city. Citizens, in fact, are increasingly active and their conception in the city has changed over time.

In the past they have played a marginal role compared to public bodies in the organization of the city, while now they are increasingly included in the decision-making and management processes. Citizen engagement creates value for all parts of a system, as they, in line with systemic thinking, must be seen as carriers of resources, informational resources (or operant resources) [4]. They are the most skilled in perceiving the challenges and seizing the opportunities of the country, for this reason, they must be completely included in smart cities, like other actors [33], as "smart people" are an essential component of smart cities [34].

"Organization" in Smart city-If "organizations" are entities that establish relationships with their stakeholders in order to create value with them, then in addition to public and private organizations, associations, in the smart city we have to consider the importance of the relationships between the different actors. Actually, the complexity of the smart city requires the existence of different actors and impose that they are all interdependent between them. The interaction of these actors gives birth to smart communities. The concept of smart community was developed by the California Institute for Smart Communities, which defines them as "communities where businesses, citizens and public bodies understand the potential of information technology and undertake know-how to use this technology to improve quality of life and working standards of their region significantly". Smart communities and integration of human capital within a city, leads to the city development and its economic growth. In this regard, Coe et al. [35] argued that a smart community comes from a participative community.

"Shared information" in Smart city_In S-D logic, Vargoand Lusch [5] argue that resources exchanged can be operand resources (tangible) or operant resources (intangible). Following this classification, in a smart city is it possible to distinguish two main kind of resource: tangible (such as monetary capital, raw material, etc.) and intangible (operant resources such as skills, knowledge, experience, know-how culture, habits, etc.).

In a smart city sharing information is also linked to environmental sustainability as it allows a diffusion of knowledge and awareness of the risks to the environment that are all the more known the more we try to fight. Likewise, social 
sustainability is also linked to shared information as it fosters participation that contributes to the increase of the sense of belonging of citizens.

The presence of more sustainable conditions in developed cities rather than in rural areas, due to less waste of energy and the use of green means [2], depends on a greater awareness of the risks that the waste of natural resources can entail. This awareness derives from a greater possibility of sharing information within smart cities.

"Technology" in Smart City-Both in the smart city and in the service systems, technology plays a fundamental role.

It is transversal to the various components of the service system and the smart city, representing a mean, not an end, since it is the indispensable prerequisite for enabling communication between the various parts.

The technology also acts as a facilitator for the creation of a new type of innovative environment that requires the balancing of creative skills, the creation of innovation-oriented institutions and collaborative networks. The emergence of such environment requires integration of technologies with systems, infrastructures, services and skills within an organic network that is sufficiently complex for the emergence of knowledge. Knowledge exchange leads to the value co-creation.

The technologies present in a smart city are innumerable, a classification of technologies that power up the development of smart cities' applications is provided by Marouli and Lytras [36] that divide them in: Content Management Systems; Networking Technologies; Data Warehouses; Analytics and Business Intelligence; Emerging Technologies; Smart City Innovation.

\section{The Configuration of the Smart City as a Service System}

Based on what has been discussed in the previous paragraphs, it can be inferred that cities are not considered only as an object of innovation, but also as ecosystems [31] that enable collective intelligence and capacity of co-creation of citizen communities for the design of innovative lifestyles and work scenarios [37]. Moreover, the application of the service system to the smart city confirm this vision, highlighting common aspects between the smart city and the service system. These aspects allow configuring the smart city as a service system.

The first aspect is linked to the regard toward the human factor and the collaborative features among the elements of the city, linked to a reticular view of the relationships among stakeholders, in which everyone is a bearer of knowledge, including citizens who are becoming more and more powerful and important. The overcoming of the internal verticalization of the administration, in favour of a landing towards a horizontal dimension of government allows understanding in a unitary and harmonized way the different vertical functions (for example the sectors of smart energy, smart house, smart building, etc.) on the market. The overcoming of old management logics allows all the actors of the system to have equal rights.

The second aspect in common between the two systems is the organic and ho- 
listic approach to the reorganization of the territory and the context in which a company operates in general that allows to integrate, enhance and direct towards common objectives, solutions and interventions. In particular, both the objectives of the service system and the smart city are: effectiveness, efficiency and sustainability. To make this integration happen it is necessary that all the resources within the city or the system enjoy equal rights and power and that they are placed on the same level. The resources exchanged by citizens take on the same role as those exchanged by organizations, for this reason, it can talk about democratization of the role of resources.

Lastly, the third aspect in common is the interacting between human and technological components. Specifically, while the human component is linked to the creation of knowledge and innovation, the technology is the mean by which knowledge is exchanged faster. The main role of ICTs, indispensable both in smart cities and in service systems, generates e-government stands as a connecting point between the two concepts. From the moment the whole city becomes an integrated system of resources that interconnect with each other in order to co-create value, then the smart city can be seen in all respects as a service system.

Finally, it can affirm that thanks to the integration of all the resources available within a city, deriving from the collaboration of the citizens themselves, it is possible to frame the whole city as a huge service system within which public value is co-created and in which citizens become central actors contributing to the value co-creation. Figure 2 summarizes this process, defining the key elements of the service system and qualifying for each of them the types of resources exchanged, used technologies, and interacting actors.

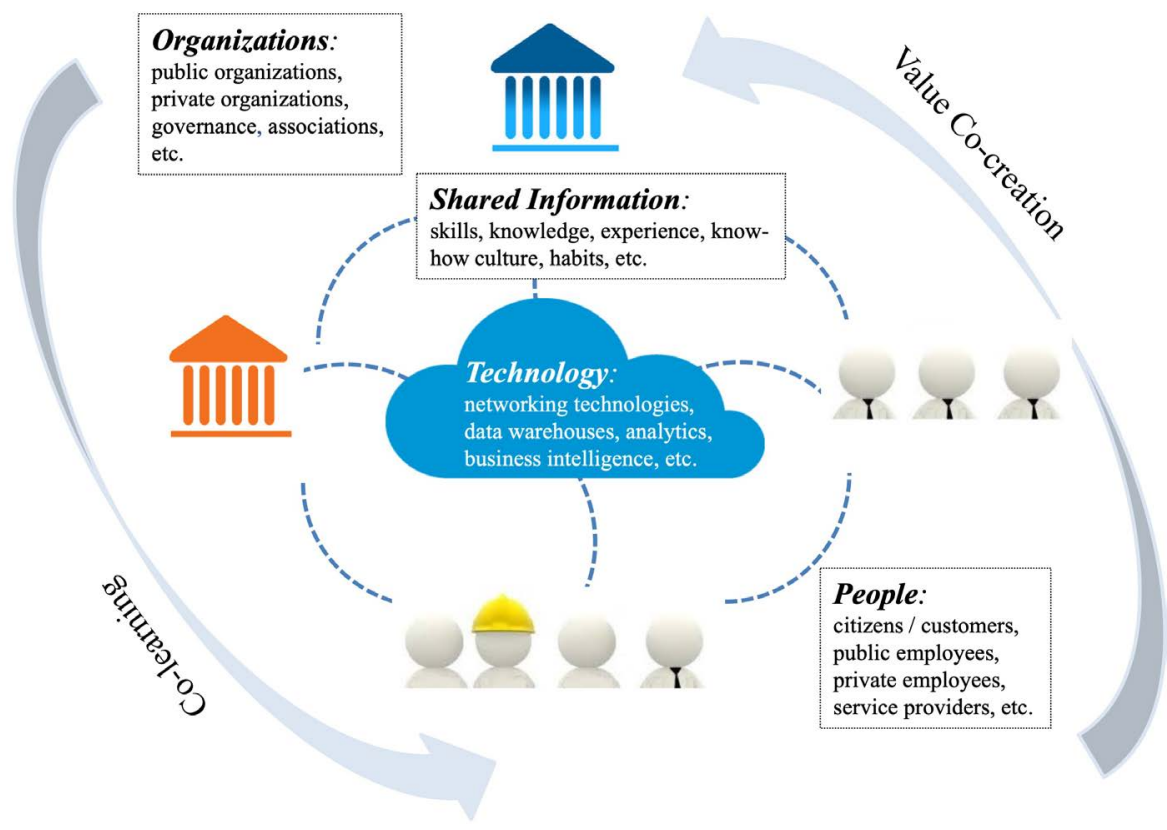

Figure 2. The configuration of the smart city as a service system. 


\section{Conclusions}

The application of the principles of the service system to the context of smart cities allows providing insights to researchers and public managers for government management. The re-conceptualization of the smart city as a service system, in fact, helps public managers to understand that a smart city should be managed as a service system, taking into account the relationships between people and organizations which, by sharing information and knowledge, allow value co-creation. Knowledge exchange represents the main element of exchange in the system. It is made indispensable by the presence of the citizens (people), and this is why the citizen engagement should be not only seen as a mean but also an ultimate end, a model to seek. Citizen and, more generally, actor engagement brings mutual resources and knowledge exchange that lead to value co-creation [4] that, in turn, in the long run, foster innovation [38]. In order to foster mutual exchange and co-learning processes, it is necessary that organizations aim at the training of the staff, especially the communication skills to favour the communication exchange with the citizen.

These exchange processes are made more efficient by the technology, which should be used as an accelerator of the co-learning processes between administrators and citizens. Within this service system, communication between actors has to be encouraged in the most transparent way possible. A direct line with the citizens reduces the strategical ambiguity desired by the public decision-makers [39]. On the other hand, citizens can use ICTs to communicate disservices, share knowledge, alarm in case of natural disasters, thus contributing to the co-creation of value in the public sphere.

\section{Implications}

The proposed conceptual framework presents both theoretical and practical implications. Regarding the first one, it can be assumed that the scheme developed may be able to make a contribution to managerial literature as the aforementioned model embraces a holistic and systemic vision [40] [41] [42] which allows placing the value co-creation as a coherent link between the aspects of the two systems analyzed; moreover, the configuration of the smart city as a service system allows an enrichment of the studies concerning both the application of the service system to different fields, which demonstrates the goodness of the model [27] [43] [44] [45], and smart city management.

With regard to practical implications, the re-reading of the smart city as a service system offers organizations a tool for better service management. The optimization of value exchanges between user and supplier could help managers to modulate the offer based on the needs of consumers and to conceive new ways of delivering services aimed at stimulating the involvement of users at each level. The public decision makers could conceive practices aimed at encouraging user involvement.

The second practical consequence concerns the advantages brought by the 
proposed model to the management of relations with citizens and in particular to the determination of the different degree of involvement of the same, and then to a segmentation of the users. In fact, in addition to working on the indispensable core functional attributes of the offer, public service managers should focus on enhancing the emotional aspects of delivery, in line with the needs of today's consumer and with the experiential service concept [46].

An estimate of the intensity of the participation of users could lead to an optimal measurement of performance, directing towards an increase of the same both by the citizen who becomes increasingly active at all stages of delivery, which the provider, able to assist the customer at all times.

Regarding the strategic profile, companies are first and foremost directed towards accommodating an organizational structure that favours the emergence of consumer empowerment, thus marrying a tendentially collaborative model in which participation is born from within, through a cohesive corporate culture and an inclusion of employees in business decision-making, and then reflect outside in the involvement of consumers.

As for the tactical component, drivers for the participation of users are linked to the implementation of "e-government" practices. As seen, the use of back-office IT infrastructures such as customer Data ware-house, the on-line provision of services with their personalization, and the monitoring of online reputation through the control of telematic word-of-mouth and presence on social media sites.

In short, in the current turbulent socio-economic context, which imposes the adoption of relational marketing strategies and customer relationship management, the key to obtaining user involvement is precisely the management of relations with consumers aimed at the loyalty of themselves to achieve a long-term competitive advantage.

To the simple construction of relationships, the maintenance of the same must be added, which guarantees that long-term loyalty is generated from satisfaction. Both activities are incentivized by the use of ICT that allow optimizing costs and time.

\section{Conflicts of Interest}

The authors declare no conflicts of interest regarding the publication of this paper.

\section{References}

[1] Caragliu, A., Del Bo, C. and Nijkamp, P. (2011) Smart Cities in Europe. Journal of Urban Technology, 18, 65-82. https://doi.org/10.1080/10630732.2011.601117

[2] Naphade, M., Banavar, G., Harrison, C., Paraszczak, J. and Morris, R. (2011) Smarter Cities and Their Innovation Challenges. Computer, 44, 32-39. https://doi.org/10.1109/MC.2011.187

[3] Washburn, D. and Sindhu, U. (2009) Helping CIOs Understand "Smart City" Initiatives, Growth. 
[4] Vargo, S.L. and Lusch, R.F. (2004) Evolving to a New Dominant Logic for Marketing. J. Mark, 68, 1-17. https://doi.org/10.1509/jmkg.68.1.1.24036

[5] Vargo, S.L. and Lusch, R.F. (2008) Service-Dominant Logic: Continuing the Evolution. Journal of the Academy of Marketing Science, 36, 1-10.

https://doi.org/10.1007/s11747-007-0069-6

[6] Vargo, S.L. and Lusch, R.F. (2011) It's All B2B and beyond: Toward a Systems Perspective of the Market. Industrial Marketing Management, 40, 181-187. https://doi.org/10.1016/j.indmarman.2010.06.026

[7] Maglio, P.P., Srinivasan, S., Kreulen, J.T. and Spohrer, J. (2006) Service Systems, Service Scientists, SSME, and Innovation. Communications of the ACM, 49, 81-85. https://doi.org/10.1145/1139922.1139955

[8] Maglio, P.P. and Spohrer, J. (2008) Fundamentals of Service Science. Journal of the Academy of Marketing Science, 36, 18-20. https://doi.org/10.1007/s11747-007-0058-9

[9] Gretzel, U., Werthner, H., Koo, C. and Lamsfus, C. (2015) Conceptual Foundations for Understanding Smart Tourism Ecosystems. Computers in Human Behavior, 50, 558-563. https://doi.org/10.1016/j.chb.2015.03.043

[10] Verschuere, B., Brandsen, T. and Pestoff, V. (2012) Co-Production: The State of the Art in Research and the Future Agenda. Voluntas. International Journal of Voluntary and Nonprofit Organizations, 23, 1083-1101. https://doi.org/10.1007/s11266-012-9307-8

[11] Grönroos, C. and Ravald, A. (2009) Marketing and the Logic of Service: Value Facilitation, Value Creation and Co-Creation, and Their Marketing Implications.

[12] Lusch, R.F. and Vargo, S.L. (2014) Service-Dominant Logic: Premises, Perspectives, Possibilities. Cambridge University Press.

[13] Payne, A.F., Storbacka, K. and Frow, P. (2008) Managing the Co-Creation of Value. Journal of the Academy of Marketing Science, 36, 83-96. https://doi.org/10.1007/s11747-007-0070-0

[14] Spohrer, J., Maglio, P.P., Bailey, J. and Gruhl, D. (2007) Steps toward a Science of Service Systems. Computer, 40, 1. https://doi.org/10.1109/MC.2007.33

[15] Carrubbo, L. (2013) La Co-creazione di valore nelle destinazioni turistiche. RIREA, Roma.

[16] Bryson, J., Daniels, P. and Warf, B. (2004) Service Worlds: People, Organisations, Technologies. Psychology Press, Routledge.

[17] Washburn, D., Sindhu, U., Balaouras, S., Dines, R.A., Hayes, N. and Nelson, L.E. (2009) Helping CIOs Understand "Smart City" Initiatives. Growth, 17, 1-17.

[18] Komninos, N. (2006) The Architecture of Intelligent Cities. Proceedings of the 2 nd International Conference on Intelligent Environments, Institution of Engineering and Technology, Athens, 5-6 July 2006.

[19] Visvizi, A., Mazzucelli, C. and Lytras, M. (2017) Irregular Migratory Flows: Towards an ICTs' Enabled Integrated Framework for Resilient Urban Systems. Journal of Science and Technology Policy Management, 8, 227-242. https://doi.org/10.1108/JSTPM-05-2017-0020

[20] Seisdedos, G. (2012) Qué es una Smart City? BIT Numerical Mathematics, 188, 35-37.

[21] Cohen, B. (2012) The Top 10 Smart Cities on the Planet. Co. Exist, 11.

[22] Chourabi, H., Nam, T., Walker, S., Gil-Garcia, J.R., Mellouli, S., Nahon, K. and Scholl, H.J. (2012) Understanding Smart Cities: An Integrative Framework. 2012 
45th Hawaii International Conference on System Sciences, Maui, HI, 4-7 January 2012, 2289-2297. https://doi.org/10.1109/HICSS.2012.615

[23] Turok, I. and McGranahan, G. (2013) Urbanization and Economic Growth: The Arguments and Evidence for Africa and Asia. Environment and Urbanization, 25, 465-482. https://doi.org/10.1177/0956247813490908

[24] Li, X., Lu, R., Liang, X., Shen, X., Chen, J. and Lin, X. (2011) Smart Community: An Internet of Things Application. IEEE Communications Magazine, 49, 68-75. https://doi.org/10.1109/MCOM.2011.6069711

[25] Arasteh, H., Hosseinnezhad, V., Loia, V., Tommasetti, A., Troisi, O., Shafie-Khah, M. and Siano, P. (2016) Iot-Based Smart Cities: A Survey. 2016 IEEE 16th International Conference on Environment and Electrical Engineering (EEEIC), Florence, 7-10 June 2016, 1-6. https://doi.org/10.1109/EEEIC.2016.7555867

[26] Troisi, O., D’Arco, M., Loia, F. and Maione, G. (2018) Big Data Management: The Case of Mulino Bianco's Engagement Platform for Value Co-Creation. International Journal of Engineering Business Management, 10, 1-8. https://doi.org/10.1177/1847979018767776

[27] Polese, F., Botti, A., Grimaldi, M., Monda, A. and Vesci, M. (2018) Social Innovation in Smart Tourism Ecosystems: How Technology and Institutions Shape Sustainable Value Co-Creation. Sustainability, 10, 140. https://doi.org/10.3390/su10010140

[28] Marshall, J.D. and Toffel, M.W. (2005) Framing the Elusive Concept of Sustainability: A Sustainability Hierarchy. Environmental Science \& Technology, 39, 673-682.

[29] Hollands, R.G. (2008) Will the Real Smart City Please Stand Up? Intelligent, Progressive or Entrepreneurial? City, 12, 303-320. https://doi.org/10.1080/13604810802479126

[30] Lozano, R. (2008) Envisioning Sustainability Three-Dimensionally. Journal of Cleaner Production, 16, 1838-1846. https://doi.org/10.1016/j.jclepro.2008.02.008

[31] Zygiaris, S. (2013) Smart City Reference Model: Assisting Planners to Conceptualize the Building of Smart City Innovation Ecosystems. Journal of the Knowledge Economy, 4, 217-231. https://doi.org/10.1007/s13132-012-0089-4

[32] Spohrer, J., Piciocchi, P. and Bassano, C. (2012) Three Frameworks for Service Research: Exploring Multilevel Governance in Nested, Networked Systems. Service Science, 4, 147-160. https://doi.org/10.1287/serv.1120.0012

[33] Shark, A.R. and Toporkoff, S. (2008) Beyond e-Government \& e-Democracy: A Global Perspective. Public Technology Institute/ITEMS International.

[34] Giffinger, R. and Gudrun, H. (2010) Smart Cities Ranking: An Effective Instrument for the Positioning of the Cities? ACE: Architecture, City and Environment, 4, 7-26.

[35] Coe, A., Paquet, G. and Roy, J. (2001) E-Governance and Smart Communities: A Social Learning Challenge. Social Science Computer Review, 19, 80-93. https://doi.org/10.1177/089443930101900107

[36] Marouli, Ch. and Lytras, M.D. (2017) Smart Urban Solutions for Innovation and Sustainability: Emerging Research and Opportunities. IGI Global, Hershey, Pennsylvania.

[37] Schaffers, H., Komninos, N., Pallot, M., Trousse, B., Nilsson, M. and Oliveira, A. (2011) Smart Cities and the Future Internet: Towards Cooperation Frameworks for Open Innovation. In: Domingue, J., et al., Eds., The Future Internet. FIA 2011. Lecture Notes in Computer Science, Vol. 6656, Springer, Berlin, Heidelberg, 431-446. https://doi.org/10.1007/978-3-642-20898-0_31 
[38] Polese, F., Troisi, O., Carrubbo, L., Grimaldi, M. and Monda, A. (2018) Technology in Value Co-Creation Experiences: How ICTs Shape Customer Activities before, during and after Delivery in Smart Tourism Systems. In: Cantino, V., Culasso, F. and Racca, G., Eds., Smart Tourism, McGraw-Hill, Milano, 523-547.

[39] Eisenberg, E. (1984) Ambiguity as Strategy in Organizational Communication. Communication Monographs, 51, 227-242. https://doi.org/10.1080/03637758409390197

[40] Mele, C. and Polese, F. (2011) Key Dimensions of Service Systems in Value-Creating Networks. In: Demirkan, H., Spohrer, J. and Krishna, V., Eds., The Science of Service Systems. Service Science: Research and Innovations in the Service Economy, Springer, Boston, MA, 37-59. https://doi.org/10.1007/978-1-4419-8270-4_3

[41] Wieland, H., Polese, F., Vargo, S. and Lusch, R. (2012) Toward a Service (Eco)Systems Perspective on Value Creation. International Journal of Service Science, Management, Engineering, and Technology (IJSSMET), 3, 12-25.

[42] Pels, J., Polese, F. and Brodie, R.J. (2012) Value Co-Creation: Using a Viable Systems Approach to Draw Implications from Organizational Theories. Mercati $e$ Competitività, No. 1/12, 19-38.

[43] Botti, A., Monda, A., Pellicano, M. and Torre, C. (2017) The Re-Conceptualization of the Port Supply Chain as a Smart Port Service System: The Case of the Port of Salerno. Systems, 5, 35. https://doi.org/10.3390/systems5020035

[44] Botti, A., Grimaldi, M., Monda, A. and Vesci, M. (2017) Smart Service Systems in Restaurant Management: A Case Study Analysis. In: Service Dominant Logic, Network and Systems Theory and Service Science: Integrating Three Perspectives for a New Service Agenda, Proceedings of the 5 th Naples Forum, Sorrento, Italy, 6-9 June 2017.

http://www.naplesforumonservice.it/uploads/files/Botti\%20Grimaldi\%20Monda\%2 0Vesci\%202.pdf

[45] Troisi, O., Sirianni, C.A., Monda, A. and Grimaldi, M. (2018) ICTs and Engagement Platforms in Resource Integration: Threat or Opportunity for Value Co-Creation? Esperienze d'Impresa.

[46] Pine, B.J. and Gilmore, J.H. (2000) Oltre il servizio: L'economia dell'esperienza. Etas. 